\title{
Nuances of Arteriovenous Fistula Creation for Vascular Access in Hemodialysis
}

\author{
Parag Sahasrabudhe ${ }^{1,2}$ Ameya Bindu ${ }^{3}$ \\ ${ }^{1}$ Department of Plastic Surgery, B.J. Govt. Medical College \& \\ Sassoon Hospitals, Pune, Maharashtra, India \\ ${ }^{2}$ Depatment of Plastic Surgery, Deenanath Hospital, Pune, \\ Maharashtra, India \\ ${ }^{3}$ Depatment of Plastic Surgery, Tata Memorial Hospital, Mumbai, \\ Maharashtra, India \\ Indian J Plast Surg 2021;54:257-263.
}

\begin{abstract}
Address for correspondence Parag Sahasrabudhe, MCh, Plot 82 Lane 2, Natraj Society, Karve Nagar, Pune 411 052, Maharashtra, India (e-mail: drparags@gmail.com).
\end{abstract}

\begin{abstract}
Keywords

- arteriovenous fistula

- vascular access

- guidelines

- hemodialysis

- chronic kidney disease

- ESRD

Background With rising incidence and increased life expectancy of patients with chronic kidney disease (CKD) and end-stage renal disease (ESRD), the number of patients requiring hemodialysis has increased substantially. Vascular access is the lifeline for a patient on hemodialysis (HD), and an arteriovenous fistula (AVF) is the undisputed gold standard for HD access. An effective and long-lasting fistula serves to increase the life expectancy of ESRD patients and improves their quality of life.

Learning Objectives This paper aims to give a comprehensive overview of AVF creation, including the various techniques, patient selection, troubleshooting with decision-making, and common complications. Authors share their experience from previous publications and over 2000 AVF surgeries. They have not only described a new modification of the technique of proximal fistula but have also established a direct correlation between bruit and thrill on operation table and success of fistula surgery. Conclusion A standardized, protocol-driven multidisciplinary approach with careful patient and site selection, guided by outcome predictors, is vital in AVF surgery. Knowledge about the potential complications of AVFs contributes to their timely detection and allows measures to be taken that might prevent deleterious consequences that range from loss of vascular access to serious morbidity and mortality.
\end{abstract}

\section{Introduction}

The estimated prevalence of chronic kidney disease (CKD) in India is $17.2 \%$, with approximately 130,000 patients on dialysis and annual growth of 10 to $20 \% .^{1-4}$ In patients on long-term renal replacement therapy (RRT), the major challenge is inadequate dialysis facilities \& support systems, nonaffordability, vascular access issues, and lack of surveillance systems, leading to a high dropout rate. Vascular access is the lifeline for a patient on hemodialysis (HD), aptly described as the Achilles heel due to associated morbidity. ${ }^{5,6}$ By creating an

published online

September 8, 2021
DOI https://doi.org/

$10.1055 / \mathrm{s}-0041-1734576$ ISSN 0970-0358 effective and long-lasting arteriovenous fistula (AVF), we can improve life expectancy and quality of life for these patients.

Only 9 to $13 \%$ of CKD patients in need of HD have AVF created before initiation of dialysis. ${ }^{7}$ A holistic multidisciplinary center with monitoring and surveillance programs goes a long way to achieve this objective. Primary physicians or nephrologists have to consider the resources, longevity, and affordability of patients before recommending AVF. It is imperative to identify the site and preserve the veins by avoiding venipuncture. 


\section{Ideal Vascular Access and Options}

International guidelines and various study groups such as National Kidney Foundation-Kidney Disease Outcomes Quality Initiative (NKF-KDOQI) 2006 CPG 2.1 (Clinical Practice Guidelines), European Best Practice Guidelines, and Canadian Society of Nephrology recommend autogenous, native vessel AVFs over the central venous catheters (CVCs) for initiation of HD. ${ }^{8-10}$ Patients who receive dialysis across a functional AVF have lower complication rates and longer duration of event-free patency than with catheter access and arteriovenous grafts (AVGs). ${ }^{11,12,14,15}$

The ideal AVF should have early placement, easy accessibility, minimal primary failure rates, early maturation, long-term patency, and minimal complications. Despite a reported failure rate of 7 to $40 \%$ with an average of $15.3 \%$, a well-made AVF lasts as long as 10 to 12 years when used carefully. ${ }^{16,17}$

The order of preference of NKF-KDOQI guidelines suggest radiocephalic, brachiocephalic, and brachiobasilic transposition fistulae and then prosthetic grafts as vascular access options. ${ }^{8.9}$

\section{Arteriovenous Fistula}

Brescia, Cimino, Appell and Hurwich (1966-New York, US) created the first surgical subcutaneous side-to-side AVF between radial artery and adjacent superficial vein and published a landmark series of 14 patients. ${ }^{18}$ Cimino fistulas are currently accepted as the ideal mode of vascular access for HD. Various factors which guide the timing of fistula creation are summarized in - Table 1. ${ }^{8.9}$ "Fistula first" initiative was implemented as the national vascular access improvement initiative, with a goal to create AVF in $50 \%$ of newly diagnosed CKDs, and to have a functioning AVF 6 months before the anticipated need for HD. ${ }^{8,9,20}$

\section{Preoperative Evaluation}

The history of recent venous injections for blood sampling or intravenous (IV) access must be accurately recorded. Any associated comorbidities like diabetes, vascular disease, history of multiple central venous catheters, collagen vascular disease, etc. should be noted ( - Table 2 )

Patient's ability to lie supine for a period of 1 to 2 hours without suffering from breathlessness is crucial. In cases of fluid overload with orthopnea, it is advisable to dialyze the patient the day before the procedure.

Clinical evaluation should include both arterial and venous assessment (-Table $\mathbf{3}$ ). The superficial venous system should

Table 1 Timing of placement of AVF (NKF guidelines)

\begin{tabular}{|l|}
\hline Creatinine clearance $-25 \mathrm{~mL} / \mathrm{min}$ or less \\
\hline Serum creatinine$-4 \mathrm{mg} / \mathrm{dl}$ or less \\
\hline Within 1 year of anticipated need of HD \\
\hline $\begin{array}{l}\text { Modified diet for renal disease estimated glomerular filtration } \\
\text { rate drops below } 15 \mathrm{~mL} / \mathrm{min}^{19}\end{array}$ \\
\hline
\end{tabular}

Abbreviations: AVF, arteriovenous fistula; HD, hemodialysis; NKF, National Kidney Foundation.
Table 2 Contraindications for AVF creation

\begin{tabular}{|c|c|}
\hline \multirow{2}{*}{$\begin{array}{l}\text { Absolute } \\
\text { contraindications }\end{array}$} & Amputation of extremities \\
\hline & $\begin{array}{l}\text { Advanced peripheral vascular disease with } \\
\text { ischemic ulcerations }\end{array}$ \\
\hline \multirow{6}{*}{$\begin{array}{l}\text { Relative } \\
\text { contraindications }\end{array}$} & Poor or suboptimal veins \\
\hline & $\begin{array}{l}\text { Low BP (normal BP for these patients is sys } \\
180 \mid 170 \text { so } 110 / 120 \text { may be a low BP for } \\
\text { these patients) }\end{array}$ \\
\hline & $\mathrm{EF}<20 \%$ or impending cardiac failure \\
\hline & $\begin{array}{l}\text { Severe orthopnea or inability to lie supine, } \\
\text { indicating overload and pulmonary } \\
\text { hypertension }\end{array}$ \\
\hline & Central venous stenosis in the same limb ${ }^{21}$ \\
\hline & $\begin{array}{l}\text { Limited life expectancy and advanced } \\
\text { disease }^{22}\end{array}$ \\
\hline
\end{tabular}

Abbreviations: AVF, arteriovenous fistula; BP, blood pressure; EF, ejection fraction.

Table 3 Preoperative vascular assessment for AVF creation

\begin{tabular}{|l|l|}
\hline Arterial requirements & Venous requirements \\
\hline $\begin{array}{l}\text { Good strong radial and brachial } \\
\text { pulsations }\end{array}$ & $\begin{array}{l}\text { Diameter of } 2-2.5 \mathrm{~mm} \\
\text { (at least } 2 \mathrm{~mm} \text { ) }\end{array}$ \\
\hline $\begin{array}{l}\text { Diameter-2 mm or more at } \\
\text { the site of anastomosis }\end{array}$ & $\begin{array}{l}\text { Straight segment within } 1 \mathrm{~cm} \\
\text { of surface }\end{array}$ \\
\hline $\begin{array}{l}\text { Patent palmar arch (Negative } \\
\text { Allen's test) }\end{array}$ & $\begin{array}{l}\text { Continuity with proximal veins } \\
\text { without any central venous } \\
\text { stenosis or obstruction }\end{array}$ \\
\hline $\begin{array}{l}\text { Pressure differential of less } \\
\text { than } 20 \mathrm{~mm} \mathrm{Hg} \text { between two } \\
\text { upper limbs }\end{array}$ & \\
\hline
\end{tabular}

Abbreviation: AVF, arteriovenous fistula.

be mapped with an outflow obstruction, using a tourniquet at the upper arm. Preferably, a straight segment should be marked, checking the compressibility, distensibility, emptying, and evidence of needle pricks or thrombophlebitis.

Although NKF guidelines advise preprocedure objective Doppler evaluation in all cases, we prefer to selectively do it only when clinical findings are inconclusive or doubtful., ${ }^{8,9}$ Central venous stenosis is clinically evident by dilated superficial veins in the axilla and lateral torso and confirmed by a Doppler examination. ${ }^{20}$

For patients with unsuitable and nondiscernible veins who are unlikely to improve with physiotherapy, the decision to do a proximal fistula should be made if early availability of vascular access is required.

\section{Decision Making for Fistula Creation}

Proximal Versus Distal AVF

The preferred sequence is distal fistula in a nondominant hand, followed by proximal brachiocephalic, and brachiobasilic fistula with or without primary vein transposition. In case of failure or nonavailability of nondominant hand, the same sequence is followed in the dominant hand. Although the proximal or brachiocephalic fistulae have lesser primary failure rates and faster maturation, they have a higher 
complication rate, such as persistent distal edema, steal phenomenon, and aneurysm formation. It is essential to advise patients and caregivers on protecting the proposed extremity from needle pricks and IV accesses.

\section{End-to-Side Versus Side-to-Side}

End of vein to side of artery anastomosis has minimum postoperative complications like distal swelling, necrosis, or ulcerations. ${ }^{23}$ In side-to-side fistula creation, authors have described a modified technique of side-to-side brachiobasilic fistula with equivalent results. ${ }^{24,25}$ It involves manual distal valve dysfunction with a vein dilator, which leads to development of forearm veins for HD access, thereby avoiding long incision for vein transposition and its complications. Basilic vein can be superficialized secondarily, if and when forearm veins become unusable, as a backup plan, without the need to create a new fistula.

The final decision on whether to opt for an end-to-side or a side-to-side anastomosis is predominantly guided by surgeon preference and local anatomical factors.

\section{Operative Technique}

Surgical creation of AVF is a day care or an outpatient procedure done under local anesthesia and loupe magnification without a tourniquet control.

\section{Distal AVF (Radiocephalic)}

A 2.5 to $3 \mathrm{~cm} \mathrm{~S}$-shaped incision is marked ( - Fig. 1 A) for adequate exposure and with a provision to extend it proximally along the course of the vein if required. Around $10 \mathrm{~mL}$ local anesthetic is infiltrated ( $2 \%$ plain lignocaine), taking care not to puncture the vein. The cephalic vein and radial artery are dissected, preserving the superficial radial nerve ( - Fig. 1 B)

The geometry of the anastomosis, that is the angle at which the vein meets the artery at site of fistula, is an important predictor of the flow and maturation. ${ }^{26}$ It is advisable to keep vein to artery angle as acute as possible $\left(18^{\circ}\right)$ to have an optimum flow across the fistula and minimum wall shear stress. ${ }^{27}$ Backflow from the vein and its lie is checked and confirmed before anastomosis. If the artery is atherosclerotic, noncompressible segment should be avoided while selecting site of arteriotomy. After securing vascular double clamps in position, an arteriotomy of approximately 6 to $7 \mathrm{~mm}$ in length is done with an 11 number surgical blade or microscissors. Anastomosis is done either in continuous or interrupted fashion with 7-0 polypropylene or 8-0 monofilament nylon. Care is taken to clip the side branches of the vein, so as to prevent the development of accessory veins and distal limb complications. Any fibrous or fascial band compressing the outflow segment of the vein is released. Skin is closed with single-layer interrupted sutures after confirming hemostasis. A noncompressible and noncircumferential dressing is given.

\section{Proximal AVF (Brachiocephalic fistula)}

The technique and operative principles of an end-to-side proximal AVF creation are similar to the distal radiocephalic fistula with a few differences (-Fig. 2) The arteriotomy size is reduced to approximately 5 to $6 \mathrm{~mm}$ because of the higher flow at brachial artery and so as to prevent any steal phenomenon and distal complications.

\section{Proximal AVF (Brachiobasilic Transposition Fistula) and Basilic Vein Superficialization}

In cases where cephalic venous system is unavailable or unsuitable for the fistula creation, basilic vein can be used. The basilic vein by virtue of its subfascial location in arm is naturally protected from damage caused by venipuncture. However, due to its deeper location, vascular access is difficult; therefore, it needs to be superficialized in the suprafascial plane and transposed anteriorly in line of cephalic vein, either in the same sitting or after maturation.

The surgical technique of superficialization includes taking a long linear incision on medial aspect of the arm, safeguarding the medial cutaneous nerve of forearm. As there are hardly any major tributaries present in this course of the vein, dissection is easy, vein is transposed anteriorly in the subcutaneous plane, and fascia is closed beneath the vein, thus superficializing it (-Fig. $\mathbf{3}$ ).

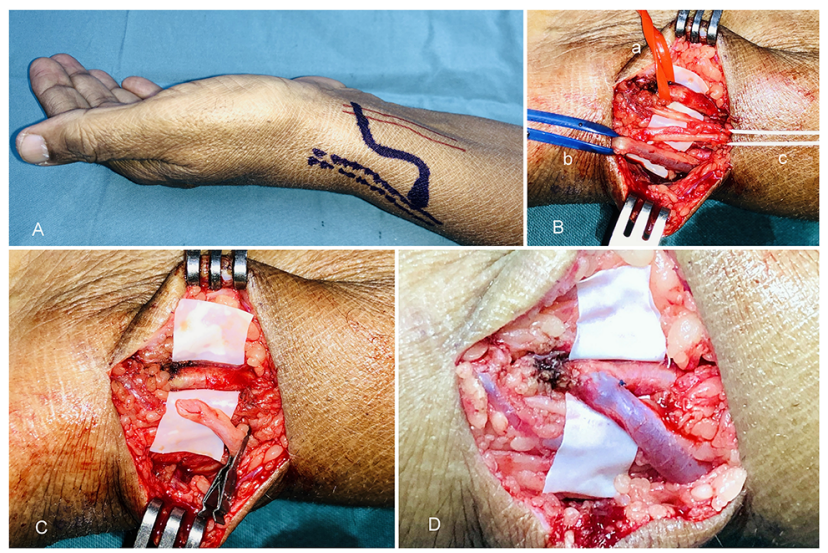

Fig. 1 Radiocephalic (distal) arteriovenous fistula (AVF). A-exploratory S-shaped incision, B-dissected radial artery (a), cephalic vein (b) with preservation of superficial radial nerve (c), C-oblique venotomy, D-completed anastomosis with dilated venous segment.
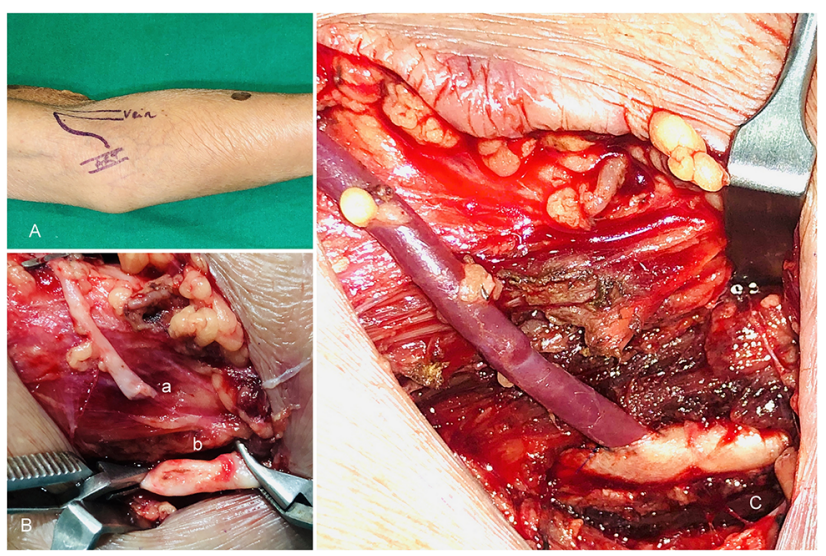

Fig. 2 Brachiocephalic (proximal) arteriovenous fistula (AVF). AExploratory $S$ shaped incision, B-adequately dissected venous segment with an oblique venotomy (a) and dissected brachial artery with a 5 to $6 \mathrm{~mm}$ arteriotomy (b), C-completed anastomosis. 

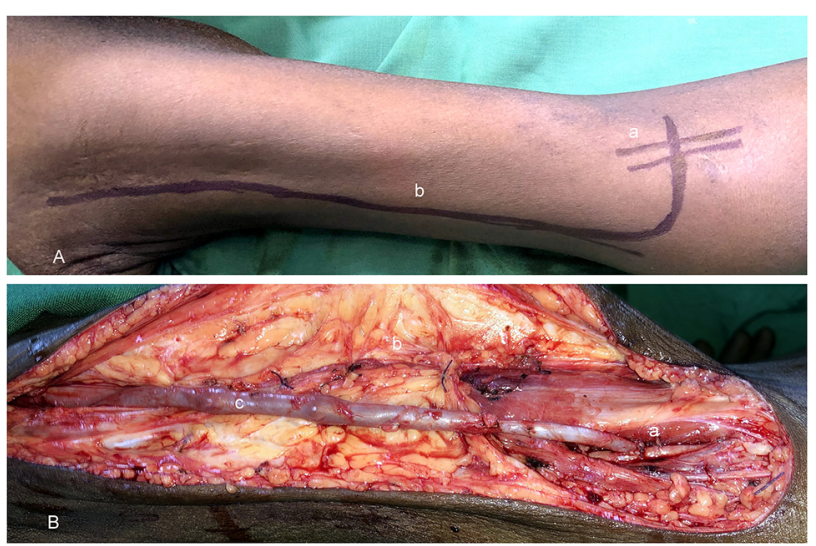

Fig. 3 Basilic vein superficialization. A-markings of basilic vein (a) and brachial artery at elbow with a long linear extension (b) of the S-shaped exploratory incision, B-completed anastomosis (a) and superficialization of the basilic vein with closure of deep fascia layer (b) below the vein and anteriorly/superficially transposed dilated basilic vein (c).

Table 4 Advantages of author's modification of proximal brachiobasilic AVF

\begin{tabular}{|l|}
\hline Small incision with limited dissection \\
\hline Lesser chances of hematoma, lymphorrhea and wound infection \\
\hline Availability of distal forearm veins as access sites \\
\hline Possibility of secondary superficialization if required \\
\hline
\end{tabular}

Abbreviation: AVF, arteriovenous fistula.

The advantages of this procedure are that it produces a long length of the straight superficial vein with a high flow rate. However, the disadvantages include need for long length of incision, increased chances of hematoma formation, requirement of regional or general anesthesia, long duration of surgery, increased stay in the hospital, and thus increase in the overall costs incurred.

\section{Author's Modification}

We have modified the technique of proximal brachiobasilic fistula to address the limitations of the conventional technique ( - Table 4)..$^{24,25} \mathrm{We}$ perform a side-to-side anastomosis between the brachial artery and basilic or median cubital vein at elbow. After completion of the posterior wall of the anastomosis with7-0 polypropylene, a long arm vessel dilator is introduced into the distal part of the basilic/antecubital vein to dysfunction the first valve toward the wrist end. This allows retrograde flow in the distal vein toward the forearm, which is confirmed by flushing it with heparinized saline and looking for thrill on the forearm. Once this flow is confirmed, the anterior wall anastomosis was completed.

\section{The Endpoint of Surgery on the Operation Table}

After completing the anastomosis, the patency and flow are confirmed by filling up the vein and palpation of thrill. Return of distal pulsations and hand vascularity is confirmed after releasing the clamps. The authors established a direct correlation between the presence of bruit heard on the table and thrill felt at the end of surgery with long-term patency and maturation of AVF. ${ }^{24}$

\section{Postoperative Care}

Patients and their relatives are instructed to avoid venipunctures on the operated side, blood pressure cuffs, tight clothing or ornaments, and any prolonged pressure. Handball exercises are taught to patients before discharge. Further, they are taught to feel the thrill every day and report to the surgeon immediately if the thrill disappears and are counselled about the warning signs like coldness, numbness, ulcers, or discoloration at fingertips. Anticoagulation is given in the form of single dose of low-molecular weight heparin (LMWH) (1 mg/kg body weight). Patients are called for review at around day 3 for first follow-up and then on 10 to 12 days where the thrill is assessed and sutures are removed, and again reviewed at 4 weeks, for features of maturation.

\section{Mature and Useable Fistula - Characteristics and Guidelines}

Primary fistula failure is defined as poor blood flow across a fistula $(<250 \mathrm{~mL} / \mathrm{min})$ not sustained for a minimum of 3 hours even after to 12 weeks of its creation. Average time taken for the fistula to mature is 4 to 6 weeks. ${ }^{28}$

The flow across the fistula multiplies to five to 10 times that of the normal arterial flow. Intraoperative flow measurements immediately after fistula creation are also a good predictor to assess the eventual maturation of an AVF. ${ }^{29}$ The average time a nephrologist advises the fistula to be used for the HD is 6 to 8 weeks, in accordance with the rule of 6 proposed by KDOQI ( - Table 5$)^{8,9}$

The main reason for the failure of maturation of a functioning fistula is undiagnosed central venous stenosis or proximal obstruction. Such cases do benefit from addressing the underlying cause by endovascular techniques.

\section{Troubleshooting for Fistula Surgery}

\section{No backflow from the vein}

Having a good backflow from the proximal end of the vein is a good predictor of proximal patency and continuity with central veins, although it is not an absolute prerequisite. Palpating for a thrill when the vein is flushed with heparinized saline with a blunt $24 \mathrm{G}$ IV cannula tip with a $5 \mathrm{~mL}$ syringe is a good maneuver to confirm the same and rule out central venous stenosis in case of the absence of backflow.

Table 5 "Rule of 6" for a mature AVF (KDOQI guidelines)

\begin{tabular}{|l|}
\hline Vein within $0.6 \mathrm{~cm}$ of skin surface \\
\hline External diameter $>6 \mathrm{~mm}$ \\
\hline $\begin{array}{l}\text { Relatively straight segment of easily accessible vein for cannula- } \\
\text { tion-at least } 6 \mathrm{~cm}\end{array}$ \\
\hline Blood flow $>600 \mathrm{~mL} / \mathrm{min}$. to support dialysis \\
\hline $\begin{array}{l}\text { To be evaluated for nonmaturation at } 4-6 \text { weeks if above criteria } \\
\text { are not met }\end{array}$ \\
\hline
\end{tabular}

Abbreviation: AVF, arteriovenous fistula; KDOQI, Kidney Disease Outcomes Quality Initiative. 


\section{No pulsations or thrill or bruit}

Absence of any pulsations or thrill postanastomosis indicates a technical problem like including the backwall in a suture, inadequate adventectomy, severe torsion or kink, or too much traction on the vessels, due to improper siting of the arteriotomy, soft thrombus at the anastomosis, a fascial band compressing the vein causing outflow obstruction, or a proximal obstruction.

\section{Role of anticoagulation}

Authors have shown that there is no proven role of long-term postoperative heparin or aspirin in long-term patency rates, where the anastomosis was satisfactory with good thrill and bruit on table. ${ }^{30}$

\section{Early Fistula Failure or Loss of Thrill}

The absence of well-developed dilated veins for HD access or disappearance of thrill within 3 months of postoperative period or prior to maturation of fistula is termed as early fistula failure. ${ }^{31}$ Various clinical predictors which predispose to early fistula failure are small caliber vessels (artery $<2 \mathrm{~mm}$ and vein $<2 \mathrm{~mm}$ ), distal AVFs, female gender, obesity, diabetes, vascular disease, suboptimal blood flow on the table or on the first postoperative day, and surgeon-related factors of

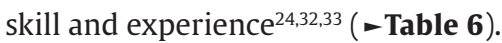

Interventional radiologists can also play a role in salvaging an early as well as late failing fistula due to thrombosis or stenotic lesions, with thromboembolectomies or dilatations by endovascular techniques, but their application is limited because of cost constraints. ${ }^{34-37}$

\section{Predictors of Outcome- Factors Affecting Fistula Maturation and Patency Rates}

In our study of patency and outcomes of 505 AVFs using logistic regression with success and immediate failure as the dependent variables, we have drawn various conclusions and recommendations, which are as follows: ${ }^{24}$

1. Presence of on table thrill and bruit has a direct and statistically significant relation with success and maturation of fistulas.

2. Patients with vein diameter $<2 \mathrm{~mm}$ are 5.4 times more prone to fistula failure.

3. There is no significant association between side of arm used, site of fistula creation, type of anastomosis and suture material, and success rate.

Table 6 Etiological factors for fistula failure

\begin{tabular}{|l|l|l|}
\hline $\begin{array}{l}\text { Immediate } \\
\text { failure }\end{array}$ & $\begin{array}{l}\text { Nonmaturing } \\
\text { AVF }\end{array}$ & Delayed failure \\
\hline Improper selection & $\begin{array}{l}\text { Juxta anastomotic } \\
\text { stenosis }\end{array}$ & Late thrombosis \\
\hline Technical failure & Accessory veins & $\begin{array}{l}\text { Hypotensive } \\
\text { episode }\end{array}$ \\
\hline Early thrombosis & $\begin{array}{l}\text { Central venous } \\
\text { stenosis }\end{array}$ & $\begin{array}{l}\text { Cephalic arch vein } \\
\text { stenosis }\end{array}$ \\
\hline
\end{tabular}

Abbreviation: AVF, arteriovenous fistula.
4. Postoperative long-term anticoagulation has no major beneficial role in eventual patency rates in uncomplicated fistula surgery.

\section{Long-Term Complications}

Distal limb edema, ulcerations, gangrenous fingertips, limb hypertrophy, and lymphorrhea.

The occurrence of swelling or edema in the distal extremity is one of the more commonly seen complications in side-to-side fistulas. This may predispose to distal necrosis and ulcerations too due to venous hypertension. Persistent hyperdynamic circulation and venous hypertension may also lead to limb hypertrophy in chronic setting, needing fistula closure in severe cases. ${ }^{38}$

In cases of proximal brachiocephalic or brachiobasilic fistula with vein transposition, the medial lymphatic outflow track may be damaged due to dissection and long incision and may predispose to lymphedema distally or lymphorrhea at elbow in rare cases, which is usually self-limiting and managed conservatively. Distal edema can be managed with limb elevation, gentle compression dressings, and physiotherapy with antegrade massage in most cases. In selected cases, surgical ligation of accessory veins might be necessary to limit the distal runoff, which can be performed transcutaneously.

\section{Aneurysm and Pseudoaneurysm Formation}

Aneurysms and pseudoaneurysms are localized vascular dilatations which can either be venous or arterial. Venous aneurysms generally occur at the site of needle pricks due to repeated punctures at the same site, as done in the button-hole technique (preferred as less painful) of pricking a fistula. ${ }^{39}$ It is advised to follow the step ladder technique, where the prick site is changed to avoid this complication. They should be evaluated for impending rupture with skin ulcerations and ligated and excised electively under tourniquet control and regional anesthesia.

\section{Steal Phenomenon/Ischemic Steal Syndrome}

The steal phenomenon entails that the blood from the artery flows preferentially into the low-pressure venous system through the fistula rather than to the distal arterial bed, creating a zone of distal arterial insufficiency..$^{40,41}$ It is common in patients with severe atherosclerosis, in arteries distal to AVF site (especially in proximal AVF), and in diabetic patients. ${ }^{42}$

\section{Thrombosis/Stenosis of Fistula}

KDOQI guidelines define significant stenosis of the vessel lumen as a reduction by more than $50 \% .^{8,9}$ Stenosis can also occur due to extraluminal compression by an abscess, hematoma, or seroma. Clinical suspicion of stenosis is confirmed by the presence of several factors like reduced quality of dialysis, prolonged bleeding after AVF puncture, pain in the area of the fistula, or increased venous pressure. Various options available to deal with these complications are thromboembolectomy, angioplasty with or without stenting, or surgical creation of a new fistula. 


\section{Cardiac Overload and Failure}

Cardiac complications are better avoided than managed by careful preoperative patient selection. They are more commonly seen in patients with preexisting chronic heart disease (low-ejection fraction [EF]) and large diameter fistulas. ${ }^{43}$

The salvage of failing fistula by radiological interventions has a high immediate technical success rate but a 1 year patency rate of $32 \%$, needing multiple interventions for salvage and functionality (3.3 procedures per fistula); thus, it may not be cost-effective. ${ }^{8,34,35,44}$ We prefer to perform a new fistula when the previous has failed or has inadequate flow rates on HD, as the morbidity, longevity, as well as costs for radiological fistula salvage are inferior when compared with new fistula creation

\section{Recent Advances and Other Options}

\section{Gracz Arteriovenous Fistula}

Gracz AVF was described at the elbow with equivalent results and patency rates to conventional side-to-side fistulas. ${ }^{45}$ The anastomotic site is below the elbow crease. The perforating vein between the superficial (median cubital or cephalic) and deep venous system is disconnected and its end is anastomosed in end-to-side fashion to brachial artery or radial artery just after its take off. This leads to the development of a Y-shaped venous system of cephalic as well as basilic vein.

\section{Synthetic Grafts}

Prosthetic AVGs are considered as secondary or tertiary access modalities to autogenous AVFs. ${ }^{46,47}$ The available graft materials can be either biological or the more commonly used synthetic ones like Dacron and PTFE grafts. They are generally created at the elbow or axilla, with a looped graft distal to the major vessels.

The major drawbacks with synthetic grafts are that they are more prone to complications and associated with higher patient morbidity and low primary and secondary patency rates, needing more interventions for salvage. ${ }^{48}$

\section{Conclusion}

The construction of a native autologous AVF on the arm or forearm is considered gold standard over prosthetic grafts and CVCs as vascular access for HD. Early referrals, thorough preoperative evaluation, careful patient and site selection, standard operative procedures, dedicated multidisciplinary team approach, and fistula care postsurgery are key factors to getting consistent results.

\section{Author Contributions}

Both the authors were involved equally in the construction, writing, editing, and review process of the manuscript of CME article on nuances of arteriovenous fistula creation for vascular access for hemodialysis.

\section{Statement}

This study was performed, and manuscript was written conforming to the Declaration of Helsinki.

\section{Disclosure Statement}

No financial disclosures. No disclosures of any relationship of any author with a commercial company that has a direct financial interest in subject matter or materials discussed in article or with a company making a competing product.

\section{Financial Support or Sponsorships \\ None.}

\section{Conflicts of Interests \\ None declared.}

\section{Acknowledgments}

The authors are thankful toward all the colleagues, hospital team, and the patients who helped us to understand and develop a multidisciplinary, protocol-driven approach toward CKD management.

\section{References}

1 Singh AK, Farag YM, Mittal BV, et al. Epidemiology and risk factors of chronic kidney disease in India - results from the SEEK (Screening and Early Evaluation of Kidney Disease) study. BMC Nephrol 2013;14:114

2 Varughese S, Abraham G. Chronic kidney disease in India: a clarion call for change. Clin J Am Soc Nephrol 2018;13(5):802-804

3 Agarwal SK, Dash SC, Irshad M, Raju S, Singh R, Pandey RM. Prevalence of chronic renal failure in adults in Delhi, India. Nephrol Dial Transplant 2005;20(8):1638-1642

4 Jha V. Current status of end-stage renal disease care in India and Pakistan. Kidney Int Suppl 2013;3:157-160

5 Schwab SJ. Hemodialysis vascular access: the Achilles' heel remains. Kidney Int 2007;72(6):665-666

6 Arora P, Kausz AT, Obrador GT, et al. Hospital utilization among chronic dialysis patients.J Am Soc Nephrol 2000;11(4):740-746

7 Modi G, Jha V. Incidence of ESRD in India. (Letter to editor. Kidney Int 2011;79:573

8 NKF-K/DOQI. Clinical Practice Guidelines for Vascular Access: Update 2000. Am J Kidney Dis 2001;37(1, Suppl 1):S137-S181

9 NKF-K/DOQIVascular Access Work group. Clinical Practice Guidelines for Vascular Access: Update. Am J Kidney Dis 2006;48(Suppl 1):s176-s322

10 Jindal K, Chan CT, Deziel C, et al. Canadian Society of Nephrology Committee for Clinical Practice Guidelines. Hemodialysis clinical practice guidelines for the Canadian Society of Nephrology. J Am Soc Nephrol 2006;17(3, Suppl 1):S1-S27

11 Tordoir JH, Van Der Sande FM, De Haan MW. Current topics on vascular access for hemodialysis. Minerva Urol Nefrol 2004;56(3):223-235

12 Young EW, Dykstra DM, Goodkin DA, Mapes DL, Wolfe RA, Held PJ. Hemodialysis vascular access preferences and outcomes in the Dialysis Outcomes and Practice Patterns Study (DOPPS. Kidney Int 2002;61(6):2266-2271

13 van Andringa de Kempenaer T, ten Have P, Oskam J. Improving quality of vascular access care for hemodialysis patients. Jt Comm J Qual Saf 2003;29(4):191-198

14 Kong NC, Morad Z, Suleiman AB. Subclavian catheters as temporary vascular access. Singapore Med J 1989;30(3):261-262

15 Roy-Chaudhury P, Kelly BS, Melhem M, et al. Vascular access in hemodialysis: issues, management, and emerging concepts. Cardiol Clin 2005;23(3):249-273

16 Huijbregts HJ, Bots ML, Wittens CH, Schrama YC, Moll FL, BlankestijnPJ;CIMINOstudygroup.Hemodialysis arteriovenous 
fistula patency revisited: results of a prospective, multicenter initiative. Clin J Am Soc Nephrol 2008;3(3):714-719

17 Gh K, Mhs M, H R, M D, L H, M N. Primary patency rate of native AV fistula: long term follow up. Int J Clin Exp Med 2012;5(2):173-178

18 Brescia MJ, Cimino JE, Appel K, Hurwich BJ. Chronic hemodialysis using venipuncture and a surgically created arteriovenous fistula. N Engl J Med 1966;275(20):1089-1092

19 Levey AS, Coresh J, Greene T, et al. Chronic Kidney Disease Epidemiology Collaboration. Expressing the modification of diet in renal disease study equation for estimating glomerular filtration rate with standardized serum creatinine values. Clin Chem 2007;53(4):766-772

20 Lok CE. Fistula first initiative: advantages and pitfalls. Clin J Am Soc Nephrol 2007;2(5):1043-1053

21 Agarwal AK, Patel BM, Haddad NJ. Central vein stenosis: a nephrologist's perspective. Semin Dial 2007;20(1):53-62

22 Moist LM, Lok CE, Vachharajani TJ, et al. Optimal hemodialysis vascular access in the elderly patient. Semin Dial 2012;25(6):640-648

23 Tordoir J, Canaud B, Haage P, et al. EBPG on vascular access. Nephrol Dial Transplant 2007;22(Suppl 2) :ii88-ii117

24 Sahasrabudhe P, Dighe T, Panse N, Deshpande S, Jadhav A, Londhe S. Prospective long-term study of patency and outcomes of 505 arteriovenous fistulas in patients with chronic renal failure: Authors experience and review of literature. Indian J Plast Surg 2014;47(3):362-369

25 Sahasrabudhe P, Dighe T, Ambekar N, et al. Study of efficacy and functionality of modified technique of proximal arteriovenous fistula as a vascular access for haemodialysis: A retrospective analysis of 171 cases. Med J DY PatilVidyapeeth 2019;12:139-144

26 Ene-Iordache B, Cattaneo L, Dubini G, Remuzzi A. Effect of anastomosis angle on the localization of disturbed flow in 'side-to-end' fistulae for haemodialysis access. Nephrol Dial Transplant 2013;28(4):997-1005

27 Pousset Y, Lermusiaux P, Berton G. Le Gouez JM, Leroy R. Numerical model study of flow dynamics through an end-to-side anastomosis: choice of anastomosis angle and prosthesis diameter. Ann Vasc Surg 2006;20(6):773-779

28 Robbin ML, Greene T, Cheung AK, et al. Hemodialysis Fistula Maturation Study Group. Arteriovenous fistula development in the first 6 weeks after creation. Radiology 2016;279(2):620-629

29 Berman SS, Mendoza B, Westerband A, Quick RC. Predicting arteriovenous fistula maturation with intraoperative blood flow measurements. J Vasc Access 2008;9(4):241-247

30 Sahasrabudhe P, Dighe T, Panse N, Patil S. Retrospective analysis of 271 arteriovenous fistulas as vascular access for hemodialysis. Indian J Nephrol 2013;23(3):191-195

31 Beathard GA, Arnold P, Jackson J, Litchfield T; Physician Operators Forum of RMS Lifeline. Aggressive treatment of early fistula failure. Kidney Int 2003;64(4):1487-1494

32 Silva MB Jr, Hobson RW II, Pappas PJ, et al. A strategy for increasing use of autogenous hemodialysis access procedures: impact of preoperative noninvasive evaluation. J Vasc Surg 1998;27(2):302-307, discussion 307-308
33 Huijbregts HJ, Bots ML, Wittens CH, Schrama YC, Moll FL, Blankestijn PJ; CIMINO study group. Hemodialysis arteriovenous fistula patency revisited: results of a prospective, multicenter initiative. Clin J Am Soc Nephrol 2008;3(3):714-719

34 Falk A. Maintenance and salvage of arteriovenous fistulas. J Vasc Interv Radiol 2006;17(5):807-813

35 Roy-Chaudhury P, Melhem M, Husted T, Kelly BS. Solutions for haemodialysis vascular access dysfunction: thinking out of the box. J Vasc Access 2005;6:3-8

36 Lee T, Roy-Chaudhury P. Advances and new frontiers in the pathophysiology of venous neointimal hyperplasia and dialysis access stenosis. Adv Chronic Kidney Dis 2009;16(5):329-338

37 Lee T, Haemodialysis vascular access dysfunction. In: Carpi A, Donaldio C, Tramonti G, eds. Progress in Haemodialysis - From Emergent Biotechnology to Clinical Practice. Rijeka: InTech; 2011 365-388

38 Bachleda P, Kojecký Z, Utíkal P, Drác P, Herman J, Zadrazil J. Peripheral venous hypertension after the creation of arteriovenous fistula for haemodialysis. Biomed Pap Med Fac Univ Palacky Olomouc Czech Repub 2004;148(1):85-87

39 Saeed F, Kousar N, Sinnakirouchenan R, Ramalingam VS, Johnson PB, Holley JL. Blood loss through AV fistula: a case report and literature review. Int J Nephrol 2011;2011:350870

40 DeCaprio JD, Valentine RJ, Kakish HB, Awad R, Hagino RT, Clagett GP. Steal syndrome complicating hemodialysis access. Cardiovasc Surg 1997;5(6):648-653

41 Zamani P, Kaufman J, Kinlay S. Ischemic steal syndrome following arm arteriovenous fistula for hemodialysis. Vasc Med 2009;14(4):371-376

42 Davidson D, Louridas G, Guzman R, et al. Steal syndrome complicating upper extremity hemoaccess procedures: incidence and risk factors. Can J Surg 2003;46(6):408-412

43 Basile C, Lomonte C, Vernaglione L, Casucci F, Antonelli M, Losurdo $\mathrm{N}$. The relationship between the flow of arteriovenous fistula and cardiac output in haemodialysis patients. Nephrol Dial Transplant 2008;23(1):282-287

44 Tan TL, May KK, Robless PA, Ho P. Outcomes of endovascular intervention for salvage of failing hemodialysis access. Ann Vasc Dis 2011;4(2):87-92

45 Bender MH, Bruyninckx CM, Gerlag PG. The Gracz arteriovenous fistula evaluated. Results of the brachiocephalic elbow fistula in haemodialysis angio-access. Eur J Vasc Endovasc Surg 1995;10(3):294-297

46 Miller PE, Carlton D, Deierhoi MH, Redden DT, Allon M. Natural history of arteriovenous grafts in hemodialysis patients. Am J Kidney Dis 2000;36(1):68-74

47 Akoh JA. Prosthetic arteriovenous grafts for hemodialysis. J Vasc Access 2009;10(3):137-147

48 Mosquera D. Regarding "Vascular access survival and incidence of revisions: a comparison of prosthetic grafts, simple autogenous fistulas, and venous transposition fistulas from the United States Renal Data System Dialysis Morbidity and Mortality Study" J Vasc Surg 2003;37(1):238-239 